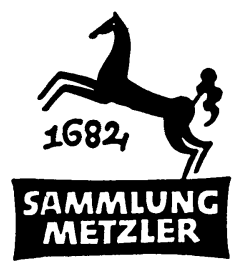

REALIEN ZUR LITERATUR

ABT. D

LITERATURGESCHICHTE 


\section{Kritische Theorie}

Horkheimer, Adorno, Marcuse, Habermas

J. B. METZLERSCHE VERLAGSBUCHHANDLUNG STUTTGART 
CIP-Kurztitelaufnahme der Deutschen Bibliothek

Gmünder, Ulrich:

Kritische Theorie: Horkheimer, Adorno, Marcuse, Habermas /

Ulrich Gmünder.

- Stuttgart : Metzler, 1985 -

(Sammlung Metzler : M 220 : Abt. D, Literaturgeschichte)

ISBN 978-3-476-10220-1

NE: GT

M 220

ISBN 978-3-476-10220-1

ISBN 978-3-476-03924-8 (eBook)

DOI 10.1007/978-3-476-03924-8

(C) 1985 Springer-Verlag GmbH Deutschland

Ursprünglich erschienen bei J. B. Metzlersche Verlagsbuchhandlung und Carl Ernst Poeschel Verlag GmbH in Stuttgart 1985 
0 Einleitung und biographische Information......... 1

0.1 Einleitung..................... 1

0.2 Zur Biographie der Kritischen Theoretiker....... 10

1 Das Programm der Sozialforschung und die Philosophie Max Horkbeimers ....................... 16

1.1 Sozialphilosophie als Sozialforschung . ........ 16

1.1.1 Programmatische Aussagen Max Horkheimers und wichtige Arbeiten der Mitglieder des Instituts für So-

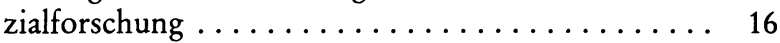

1.1.2 Die Grundthesen der frühen Kritischen Theorie . . . . . 19

1.1.3 Motivation und Ziel der Kritik . . . . . . . . . . . 21

1.1.4 Methode....................... 23

1.1.5 Das Verhältnis zur marxistischen Orthodoxie...... 26

1.1.6 Kultur und Ideologie. . . . . . . . . . . . . . . . . 29

1.1.7 Realgesellschaftliche Veränderungen und Defizite der frühen Kritischen Theorie . . . . . . . . . . . . . . . . 34

1.2 Die Kritik der instrumentellen Vernunft . . . . . . . . . 37

1.3 Max Horkheimers Spätphilosophie . . . . . . . . . 43

2 Die klassische Gestalt der Kritischen Theorie ......... 48

2.1 Der Verblendungszusammenhang der Eindimensionalität..................... 48

2.2 Die Dialektik der Aufklärung $\ldots \ldots \ldots \ldots \ldots \ldots 58$

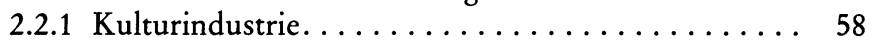

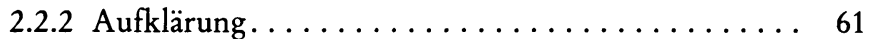

2.3 Unterschiedliche Heilmittel. . . . . . . . . . . . 67

2.3.1 Die negative Dialektik als Modell nicht-identifizierenden Denkens. . . . . . . . . . . . . . . . . . . . 67

2.3.2 Die Logik des Ästhetischen als Spur des Nichtidentischen ...................... 74

2.3.3 Reale Praxis als Ausfluß einer $>$ Neuen Sensibilität‘. . . 81

2.4 Kritik der klassischen Gestalt der Kritischen Theorie

2.5 Exkurs: Die empirischen Arbeiten des Instituts für Sozialforschung und der Positivismusstreit. . . . . . 90

2.5.1 Die empirischen Arbeiten des Instituts für Sozialforschung ...................... 90

2.5.2 Der Positivismusstreit................ 94 
3 Herbert Marcuses ästhetische Utopie . . . . . . . . . . . 102

3.1 Der Sprung aus der Geschichte - Psychoanalyse und Ästhetik . . . . . . . . . . . . . . . . . . . . . . 102

3.2 Die erotisierte Psychoanalyse .............. 104

3.3 Die >Neue Sensibilität<: Spiel und Arbeit, Kunst und Technik-Resurrektion der Natur? . . . . . . . . . . 107

4 Jürgen Habermas' Neukonstruktion Kritischer Theorie . . . 112

4.1 Einleitung und generelles Verhältnis zur Kritischen Theorie........................ 112

4.2 Die Dialektik der Aufklärung als Theorie der sozialen Evolution: Rekonstruktion der Rationalisierungsprozesse in >Arbeit $<$ und $>$ Interaktion . . . . . . . . . 116

4.3 Sprache als Fundament, Mittel und Ziel . . . . . . . 122

4.4 Transzendentale Fundierung von Wissenschaftstypen; Technik, Gesellschaft und Natur . . . . . . . . . 126

4.5 Krisen im Spätkapitalismus . . . . . . . . . . . 131

4.6 Das Ästhetische als Leerstelle und das Entschwinden des Imaginären . . . . . . . . . . . . . . . . 137

Ausgewählte Literatur . . . . . . . . . . . . . . 141 


\section{VERZEICHNIS DER SigeLN}

der fortlaufend im Text zitierten Schriften. Das angegebene Erscheinungsjahr ist jeweils das der Ersterscheinung, mit dessen Hilfe genauere Angaben der Bibliographie entnommen werden können.

AFR Marcuse, »Art as Form of Reality «, 1972

AODS Marcuse, "Art in the One-Dimensional Society «, 1967

ÄT Adorno, Ästhetische Theorie, 1970

DA Horkheimer/Adorno, Dialektik der Aufklärung, 1944

Däm Horkheimer, Dämmerung, 1934

DSH Adorno, Drei Studien zu Hegel, 1963

EI Habermas, Erkenntnis und Interesse, $1973^{2}$

FuN Marcuse, »Freiheit und Notwendigkeit«, 1970

Gs $\quad$ Marcuse, Gespräche mit Herbert Marcuse, 1978

GÜ Horkheimer, Gesellschaft im Übergang, 1942-1970

KdiV Horkheimer, Kritik der instrumentellen Vernunft, 1947

KG Marcuse, Kultur und Gesellschaft, (1965)

KR Marcuse, Konterrevolution und Revolte, 1972

LS Habermas, Legitimationsprobleme im Spätkapitalismus, 1973

ND Adorno, Negative Dialektik, 1966

PK $\quad$ Marcuse, Die Permanenz der Kunst, 1977

PP Marcuse, Psychoanalyse und Politik, 1968

PS Adorno u. a., Der Positivismusstreit in der deutschen Soziologie, 1969

PT Adorno, Philosophische Terminologie, 1973/1974

RHM Habermas, Zur Rekonstruktion des Historischen Materialismus, 1976

Sehn Horkheimer, Die Sebnsucht nach dem ganz Anderen, 1970

SS Horkheimer, Sozialphilosophische Studien, 1930-1972

TG Marcuse, Triebstruktur und Gesellschaft, 1955

TKH Habermas, Theorie des kommunikativen Handelns, 1981

TW Habermas, Technik und Wissenschaft als ,Ideologie`, 1968

VB Marcuse, Versuch über die Befreiung, 1969

VR Marcuse, Vernunft und Revolution, 1941

VW Horkheimer, Verwaltete Welt, 1970

WT Habermas, "Wahrheitstheorien «, 1973

ZfS Zeitschrift für Sozialforschung (Jahrgang/Seite)

ZM Marcuse, Zeitmessungen, 1975 